\title{
Random-Coiled Conformation of Polypeptide Chains I. Theoretical Conformational Analysis of Polypeptide Chains with Aromatic Side Chains
}

\author{
Masahito OKA and Akio NAKAJIMA* \\ Department of Polymer Chemistry, Kyoto University, \\ Kyoto 606, Japan
}

(Received March 16, 1984)

\begin{abstract}
Random-coiled conformations of poly(L-phenylalanine) and poly(L-tyrosine) were theoretically analyzed by a conformational energy calculation based on intra-residue interactions. Favorable side-chain/backbone interactions stabilizing extended conformations were found. Owing to these interactions, the characteristic ratios of poly( $\mathrm{L}$-phenylalanine) and poly(Ltyrosine) were significantly higher than that of poly(L-alanine). The theoretical characteristic ratio of poly(L-tyrosine) was in good agreement with the experimental results for the side-chain derivative of poly(L-tyrosine).
\end{abstract}

KEY WORDS Conformational Energy Calculation / ECEPP / Characteristic Ratio / Random-Coiled Conformation / Poly(Lphenylalanine) / Poly(L-tyrosine) /

Theoretical analysis of the random-coiled conformation of polypeptide chains in the unperturbed state was carried out by Flory et al., ${ }^{1-5}$ and Tanaka and Nakajima. ${ }^{6-8}$ In this analysis, 1) specific short-range interactions caused by all the atoms shown in Figure 1 except for the side-chain atoms attached to the $\mathrm{C}^{\alpha}$ atoms of the $(i-1)$ and $(i+1)$ th residues were considered. (These short-range interactions are referred to as intra-residue interactions in this paper.) 2) Side-chain/backbone interactions were approximately represented by interactions between $\beta$-methylene groups and backbone atoms, and their magnitudes were estimated as a function of the radius of $\beta$ methylene group $\left(r_{\mathrm{CH}_{2}}\right)$. The values of $1.85 \AA^{1-3}$ and $2.00 \AA^{6-8}$ were found to be compatible with the characteristic ratios obtained experimentally for poly(L-glutamic acid $)^{9}$ and its side-chain derivatives, ${ }^{10,11}$ $\operatorname{poly}(\mathrm{L}-\mathrm{lysine})^{9}$, and $\operatorname{poly}(\beta$-benzyl-L-aspar- tate). ${ }^{9}$ The above approximations are applicable only to alanine-type polypeptide chains which are defined as those having no branches at the $\beta$-carbon atom.

Miller and Goebel ${ }^{12}$ calculated the characteristic ratio of polypeptide chains composed of $\beta$-branched residues. They approximated the groups attached to the $\beta$-carbon atom by spheres on the $\gamma$-atoms having appropriate van der Waals radii. However, there is no clear theoretical background for the assumed van der Waals radii nor experimental data for those polypeptides composed of $\beta$-branched residues. Moreover, the side-chain features of non- $\beta$-branched residues such as L-Phe and LTyr cannot be treated by the above approximations.

Conformational analysis of oligopeptides $^{13-15}$ using ECEPP (Empirical Conformational Energy Program for Peptides $)^{16}$ indicates that the backbone conformations of

\footnotetext{
* To whom correspondence should be addressed.
} 
these molecules significantly depend on sidechain conformations even for non- $\beta$-branched residues. The energy functions of ECEPP are based on the experimental results and quantum chemical analysis of conformations of oligopeptides and their model molecules. However, the theoretical background for evaluating the van der Waals radii of the $\beta$-methylene group ${ }^{1-8}$ and the atomic group attached to $\beta$-carbon ${ }^{12}$ is not so clear as ECEPP.

In this paper, a theoretical analysis of the random-coiled conformation of polypeptide chains with aromatic side chains (i.e., L-Phe and L-Tyr) was carried taking into consideration intra-residue interactions. The effects of inter-residue interactions on the backbone conformation may also be important. But these points will be discussed in our next paper. $^{15}$

The effects of specific side-chain conformations on backbone conformation were analyzed, and the characteristic ratio of poly $(\mathrm{L}-$ phenylalanine) was calculated by fixing the side-chain conformation to low-energy regions in the $\left(\chi^{1}, \chi^{2}\right)$ energy space. The global effects of the aromatic side-chain groups on the relative stability of the backbone conformation are discussed, and the characteristic ratios of poly(L-phenylalanine) and poly (L-tyrosine) were calculated by averaging the chain conformation over the entire $\left(\phi, \psi, \chi^{1}, \chi^{2}\right)$ space.

\section{THEORETICAL}

The nomenclature and conventions adopted are those recommended by the IUPAC-IUB nomenclature commision. ${ }^{17}$ In Figure 1, a portion of a polypeptide chain, including the $i$ th residue and parts of both the $(i-1)$ and $(i+1)$ th residues, is represented in its fully extended conformation $\left(\phi=\psi=180^{\circ}\right)$, where $R_{i}$ denotes the substituent attached to the $\alpha$ carbon atom $\mathrm{C}_{i}^{\alpha}$ of the $i$ th residue. The previous definitions ${ }^{1-8}$ of $\eta, \xi$, and $\theta$ were used except that their values slightly differed from the previous ones because of the difference in geometries. The planarity of $\mathrm{C}^{\alpha}-\mathrm{C}^{\prime}-\mathrm{N}-\mathrm{C}^{\alpha}$ bonds was assumed, ${ }^{1-8}$ and the polypeptide chain represented by a chain composed of virtual bonds connecting $\mathrm{C}^{\alpha}$ atoms. With these assumptions, the rotations around the virtual bonds can be treated as independent of the rotational states of the adjacent bonds; that is, conformational states of polypeptide chains in the random-coiled state can be specified by the intra-residue interactions for each residue.

The partition function of a polypeptide chain can be represented by the product of the partition functions of individual residues. The partition function $Z_{i}$ of the $i$ th residue is expressed in terms of the conformational energy $E_{i}$ of the $i$ th residue as

$$
Z_{i}=\int \cdots \int \exp \left\{-\beta E_{i}\left(\phi_{i}, \psi_{i}, \chi_{i}\right)\right\} \mathrm{d} \phi_{i} \mathrm{~d} \psi_{i} \mathrm{~d} \chi_{i}
$$

where $\beta=1 / R T$, and $R T$ is the gas constant times the temperature. The matrix $\boldsymbol{T}_{i}$ transforming the coordinate system attached to the $i+1$ th bond to that of the $i$ th bond is given by

$$
\begin{aligned}
\boldsymbol{T}_{i} & =\boldsymbol{T}\left(\phi_{i}, \psi_{i}\right) \\
& =\boldsymbol{R}(\xi, 0) \boldsymbol{R}\left(\theta,-\phi_{i}\right) \boldsymbol{R}\left(-\eta,-\pi-\psi_{i}\right) .
\end{aligned}
$$

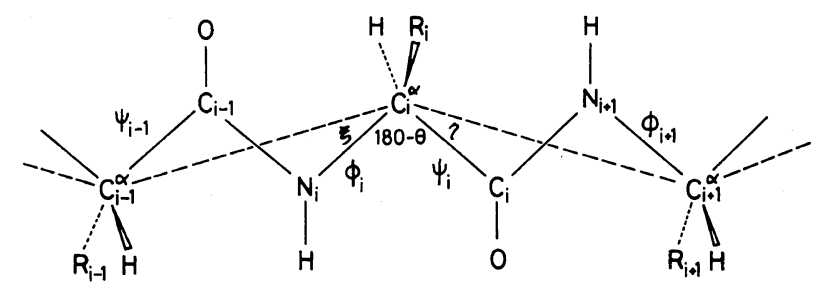

Figure 1. Fully extended polypeptide chain. 
where $\boldsymbol{R}$ is the transformation matrix given by eq B. 4 of ref 18 . Equation 2 is slightly different from the original equation by Flory ${ }^{1,18}$ because of the difference in nomenclature. The statistically averaged $\boldsymbol{T}_{i}$ over all the backbone and side-chain conformations of residue $i$ is given by

$$
\begin{aligned}
&\left\langle\boldsymbol{T}_{i}\right\rangle=Z_{i}^{-1} \int \cdots \int \boldsymbol{T}\left(\phi_{i}, \psi_{i}\right) \exp \left(-\beta E\left(\phi_{i}, \psi_{i}, \chi_{i}\right)\right. \\
& \times \mathrm{d} \phi_{i} d \psi_{i} \mathrm{~d} \chi_{i}
\end{aligned}
$$

We define the conformational energy $E_{\mathrm{av}}\left(\phi_{i}, \psi_{i}\right)$ averaged over the side-chain conformations by

$$
\begin{aligned}
& E_{\mathrm{av}}\left(\phi_{i}, \psi_{i}\right) \\
& \quad=-\beta^{-1} \ln \left[\int \cdots \int \exp \left\{-\beta E\left(\phi_{i}, \psi_{i}, \chi_{i}\right)\right\} \mathrm{d} \chi_{i}\right]
\end{aligned}
$$

By using $\langle\boldsymbol{T}\rangle\left(=\left\langle\boldsymbol{T}_{i}\right\rangle\right.$ in eq 3$)$, the characteristic ratio of polypeptide chain is represented by

$$
\left\langle R^{2}\right\rangle_{0, \infty} / n l^{2}=\left[\left(E_{3}+\langle\boldsymbol{T}\rangle\right)\left(E_{3}-\langle\boldsymbol{T}\rangle\right)^{-1}\right]_{11}
$$

where, $\boldsymbol{E}_{3}$ is the $3 \times 3$ unit matrix, the subscript 11 denotes the 1,1-element of matrix, $n$ and $l$ are the number of virtual bonds and virtual bond length, respectively.

The conformational energy $E_{i}\left(\phi_{i}, \psi_{i}, \chi_{i}\right)$ of residue $i$ was calculated for single residue peptides with two blocking end groups, acetyland $\mathrm{N}$-methylamide- (i.e., Ac-X-NHMe). All the interactions in the model peptide Ac-XNHMe are referred to as intra-residue interactions. This is slightly different from the definition mentioned in the Introduction section and also used in the previous work. ${ }^{1-8}$ In our model, additional interactions related to six hydrogen atoms attached to $C_{i-1}^{\alpha}$ and $C_{i+1}^{\alpha}$ atoms are included. However, these additional interactions have minor influence on the relative stability of the backbone conformation of residue $i$. Conformational energy calculations $^{19}$ for two model peptides, $\mathrm{C}^{\alpha}$
CO-L-Ala-NH- $\mathrm{C}^{\alpha}$ and $\mathrm{C}^{\alpha}-\mathrm{CO}-\mathrm{Gly}-\mathrm{NH}-\mathrm{C}^{\alpha}$, support the validity of our model.

Conformational energy calculations were carried out for Ac-L-Phe-NHMe and Ac-LTyr-NHMe with ECEPP ${ }^{16}$ using standard values for bond lengths and bond angles, except that the $\mathrm{C}^{\alpha}-\mathrm{H}$ bond length was $1.09 \AA$ instead of $1.00 \AA .^{20,21}$ The backbone dihedral angles $(\phi, \psi)$ were changed at $15^{\circ}$ intervals, and the two side-chain dihedral angles $\left(\chi^{1}, \chi^{2}\right)$, at $\left(120^{\circ}, 60^{\circ}\right),\left(30^{\circ}, 30^{\circ}\right)$, and $\left(15^{\circ}, 15^{\circ}\right)$ intervals to evaluate the influence of the range of intervals on the characteristic ratio. All other backbone dihedral angles were fixed at $180^{\circ}$, and $\chi^{6}$ of Tyr side chain, at $0^{\circ}$. A Tyr side chain has two energy minimum conformations with $\chi^{6}=0^{\circ}$ and $180^{\circ}$, but theoretical analysis $^{13,14}$ of peptides containing Tyr residue showed that fixing $\chi^{6}$ at either of the two angles has minor effects on the relative stability of the backbone conformation.

\section{RESULTS}

Unperturbed Chain Dimensions for Poly(Lalanine) and Poly(glycine)

For comparison, unperturbed chain dimensions of poly(L-alanine) and poly(glycine) were calculated on the basis of conformational energy calculations with intraresidue interactions of Ac-L-Ala-NHMe and Ac-Gly-NHMe, respectively. Calculations were carried out at $15^{\circ}$ intervals of $\phi$ and $\psi$, fixing $\chi^{1}$ of L-Ala at $60^{\circ}$. The energy contour map for Ac-L-Ala-NHMe thus calculated is shown in Figure 2. From the energy maps calculated, $\left\langle R^{2}\right\rangle_{0, \infty} / n l^{2}=2.15$ and 8.15 were obtained for poly(glycine) and poly(L-alanine), respectively. The following statistically averaged transformation matrices were obtained for poly(glycine) and poly(Lalanine), respectively.

$$
\langle\boldsymbol{T}\rangle_{\mathrm{Gly}}=\left[\begin{array}{rrr}
0.374 & -0.155 & 0.000 \\
0.080 & -0.446 & 0.000 \\
0.000 & 0.000 & -0.204
\end{array}\right]
$$




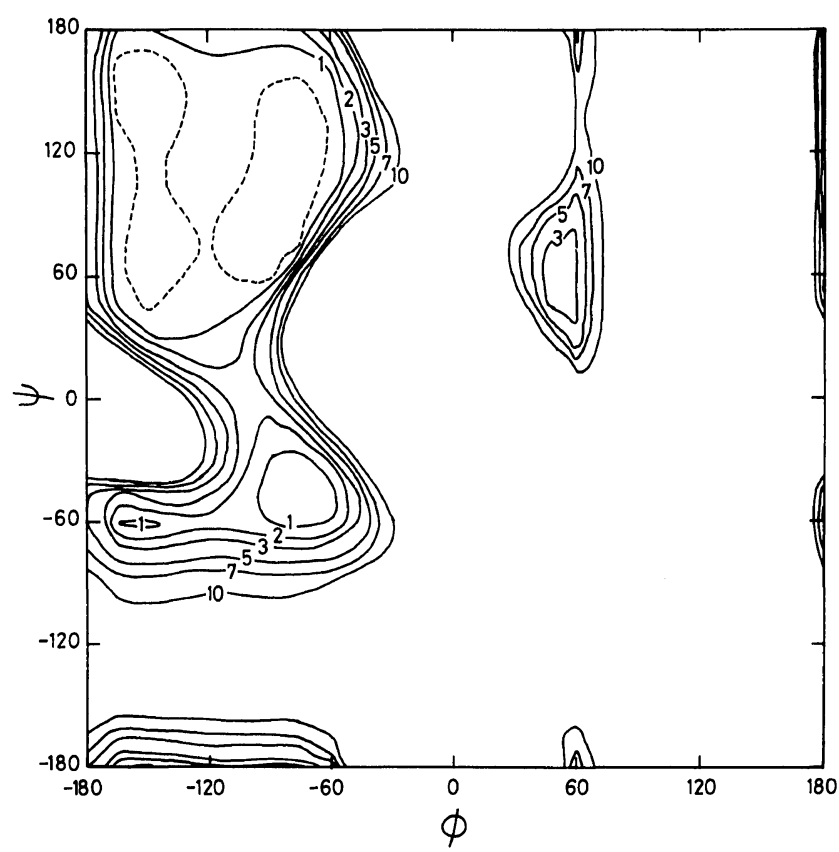

Figure 2. Energy contour $(\phi, \psi)$ map of the L-Ala residue with $\chi^{1}=60^{\circ}$ at $15^{\circ}$ intervals. The contour lines are labeled as energy in $\mathrm{kcal} \mathrm{mol}^{-1}$ above the minimum energy point. The dashed lines indicate the $0.5 \mathrm{kcal}$ $\mathrm{mol}^{-1}$ energy contour lines.

$\langle\boldsymbol{T}\rangle_{\text {L-Ala }}=\left[\begin{array}{rrr}0.379 & -0.118 & 0.666 \\ -0.032 & -0.653 & -0.119 \\ 0.749 & -0.094 & -0.273\end{array}\right]$

Effects of Side-Chain Conformations on Backbone Conformation Stabilities

To investigate the effects of side-chain conformations on the stabilities of backbone conformations, energy calculations were carried out for Ac-L-Phe-NHMe at $15^{\circ}$ intervals of two side-chain dihedral angles, $\chi^{1}$ and $\chi^{2}$, with the backbone conformation fixed at one of the following single residue minimum conformations $^{13}$ specified by $(\phi, \psi)=\left(-155^{\circ}, 147^{\circ}\right)$, $\left(-76^{\circ}, 139^{\circ}\right),\left(-85^{\circ}, 79^{\circ}\right),\left(-74^{\circ},-37^{\circ}\right)$, $\left(-147^{\circ}, 31^{\circ}\right),\left(-162^{\circ},-53^{\circ}\right)$, and $\left(49^{\circ}, 55^{\circ}\right)$ with the letter codes, ${ }^{13} \mathrm{E}, \mathrm{F}, \mathrm{C}, \mathrm{A}, \mathrm{D}, \mathrm{G}$, and $A^{*}$, respectively. The calculated $\left(\chi^{1}, \chi^{2}\right)$ energy contour maps are shown in Figure 3. Energetically favorable regions exist around $\chi^{1}=-180^{\circ},-60^{\circ}$, and $60^{\circ}$, and $60^{\circ} \leq \chi^{2} \leq$
Table I. Characteristic ratio of poly(L-phenylalanine) for specified side-chain conformations

\begin{tabular}{rrcc}
\hline \multicolumn{1}{c}{$\chi^{1}$} & $\chi^{2}$ & $\Delta E\left(\mathrm{kcal} \mathrm{mol}^{-1}\right)^{\mathrm{a}}$ & $\left\langle R^{2}\right\rangle_{0, \infty} / n l^{2}$ \\
\hline 60 & 90 & 0.000 & 133.24 \\
180 & 90 & 0.143 & 12.20 \\
180 & 60 & 0.272 & 10.43 \\
-60 & 90 & 0.630 & 11.90 \\
-60 & 120 & 0.688 & 9.76 \\
-150 & 90 & 1.916 & 23.21 \\
-90 & 90 & 2.096 & 22.26 \\
-90 & 120 & 2.194 & 24.53 \\
-150 & 60 & 2.367 & 19.38 \\
90 & 90 & 2.500 & 32.45 \\
150 & 90 & 2.685 & 76.96 \\
30 & 90 & 2.771 & 78.32 \\
\hline
\end{tabular}

a $\Delta E=E-E_{\min } ; E_{\min }=-5.983 \mathrm{kcal} \mathrm{mol}^{-1}$ for $\left(\phi, \psi, \chi^{1}\right.$, $\left.\chi^{2}\right)=\left(-155^{\circ}, 147^{\circ}, 60^{\circ}, 90^{\circ}\right)$.

$120^{\circ}$ and $-60^{\circ} \geq \chi^{2} \geq-120^{\circ}$. For the three backbone conformations with $\phi \simeq-80^{\circ}$ (i.e., $\mathrm{F}, \mathrm{C}$, and $\mathrm{A})$, stable regions in the $\left(\chi^{1}, \chi^{2}\right)$ space are independent of $\psi$. However, this 
was not the case for the three backbone conformations with $\phi \simeq-150^{\circ}$ (i.e., E, D, and $\mathrm{G}) ; 12$ stable side-chain conformations were found on the $30^{\circ}$ grid in the $\left(\chi^{1}, \chi^{2}\right)$ space with $\Delta E<3 \mathrm{kcal} \mathrm{mol}^{-1}\left(\Delta E=E-E_{\min }\right.$, $E_{\min }=-5.983 \mathrm{kcal} \mathrm{mol}^{-1}$ for $\left(\phi, \psi, \chi^{1}, \chi^{2}\right)=$ $\left(-155^{\circ}, 147^{\circ}, 60^{\circ}, 90^{\circ}\right)$. Their $\left(\chi^{1}, \chi^{2}\right)$ are listed in Table I.

By fixing the side-chain conformation at one of the low-energy conformations in Table I, $(\phi, \psi)$ energy contour maps were calculated. Some of them are shown in Figure 4. Figure 4 indicates that, as compared with the case of $\mathrm{L}^{-}$ Ala residue (Figure 2), energetically allowed backbone conformations of L-Phe residue are restricted to specific regions if the side-chain conformation of L-Phe residue is fixed at a particular conformation. For example, Figure 4a shows that only the $E$ conformation is energetically allowed for the backbone with the side-chain conformation $\left(\chi^{1}, \chi^{2}\right)=\left(60^{\circ}\right.$, $90^{\circ}$ ). For this case, the backbone may be forced to take on an ordered structure (i.e., extended structure), as is indicated by the unusually high value of $\left\langle R^{2}\right\rangle_{0, \infty} / n l^{2}$ (133.24 in Table I) compared to the characteristic ratio of other synthetic polymers in the random-coiled state. ${ }^{18}$ By comparing Figures $4 \mathrm{~b}, 4 \mathrm{e}$, and $4 \mathrm{~g}$, or Figures $4 \mathrm{c}$ and $4 \mathrm{f}$, it is evident that the backbone conformations depend significantly on $\chi^{1}$; that is, the relative stabilities of backbone conformations change significantly with small change in $\chi^{1}\left(\Delta \chi^{1}= \pm 30^{\circ}\right)$. Moreover, Figures $4 \mathrm{~b}$ and $4 \mathrm{c}$ or Figures $4 \mathrm{e}$ and $4 \mathrm{f}$ indicate that the backbone conformations also depend on $\chi^{2}$, but no so remarkably on $\chi^{1}$.

The calculated values of $\left\langle R^{2}\right\rangle_{0, \infty} / n l^{2}$ are represented in Table I. They depend significantly on the side-chain conformations and are higher than that of poly(L-alanine). These results indicate 1) that the characteristic ratio of poly(L-phenylalanine) cannot be estimated by the $\beta$-methylene group approximation, and 2 ) that the statistical averaged values calculated by fixing the side-chain conformation at a particular one may not be usable as approxi- mated values.

\section{Statistical Average Over the Entire Confor- mational Space}

In Figures 5a, 5b, and 5c, the energy contour maps of the backbone conformation of the LPhe residue averaged over the side-chain conformations $\left(\chi^{1}, \chi^{2}\right)$ at $\left(120^{\circ}, 60^{\circ}\right),\left(30^{\circ}, 30^{\circ}\right)$, and $\left(15^{\circ}, 15^{\circ}\right)$ intervals are shown, respectively. A comparison with the results for the L-Ala residue (Figure 2) shows the E conformation to be stabilized, but other conformations, especially, these of $\mathrm{C}$ and $\mathrm{D}$, to be destabilized by the side-chain/backbone interactions. The value of the interval affects to some extent the stability of the averaged backbone conformation. It can be seen in Figures $5 a-5 c$ that energetically stable regions in the $(\phi, \psi)$ map of the $\left(120^{\circ}, 60^{\circ}\right)$ intervals obviously differ from those of the $\left(30^{\circ}, 30^{\circ}\right)$ and $\left(15^{\circ}, 15^{\circ}\right)$ intervals; that is, $\mathrm{F}$ and $\mathrm{C}$ conformations are more destabilized in the $(\phi, \psi)$ map of the former intervals. As shown in Table II, the calculated characteristic ratio $\left\langle R^{2}\right\rangle_{0, \infty} / n l^{2}$ is $13.20,10.71$ and 11.24 for the $\left(120^{\circ}, 60^{\circ}\right)$, $\left(30^{\circ}, 30^{\circ}\right)$, and $\left(15^{\circ}, 15^{\circ}\right)$ intervals, respectively, and the averaged transformation matrices are

$$
\begin{aligned}
& \langle\boldsymbol{T}\rangle_{\mathrm{L}-\mathrm{Phe}}\left(120^{\circ}, 60^{\circ}\right)= \\
& \quad\left[\begin{array}{rrr}
0.595 & 0.237 & 0.575 \\
0.222 & -0.770 & 0.077 \\
0.625 & 0.013 & -0.563
\end{array}\right] \\
& \langle\boldsymbol{T}\rangle_{\mathrm{L}-\mathrm{Phe}}\left(30^{\circ}, 30^{\circ}\right)= \\
& \quad\left[\begin{array}{rrr}
0.536 & 0.149 & 0.621 \\
0.135 & -0.746 & 0.037 \\
0.671 & -0.020 & -0.480
\end{array}\right] \\
& \langle\boldsymbol{T}\rangle_{\mathrm{L}-\mathrm{Phe}}\left(15^{\circ}, 15^{\circ}\right)= \\
& \\
& {\left[\begin{array}{rrr}
0.538 & 0.146 & 0.625 \\
0.147 & -0.748 & 0.034 \\
0.674 & -0.006 & -0.476
\end{array}\right]}
\end{aligned}
$$


M. OKA and A. NAKajIMA

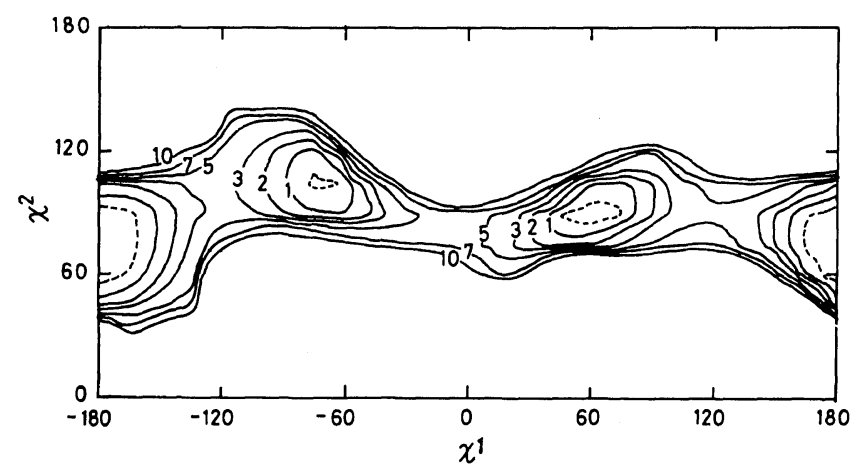

(a)

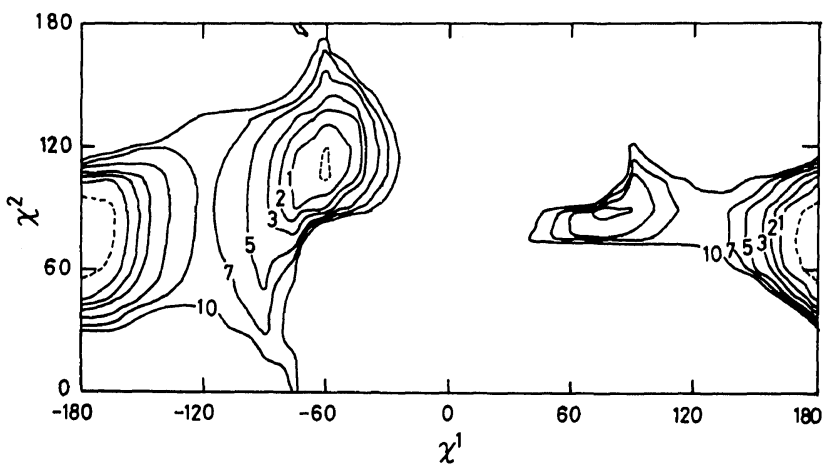

(b)

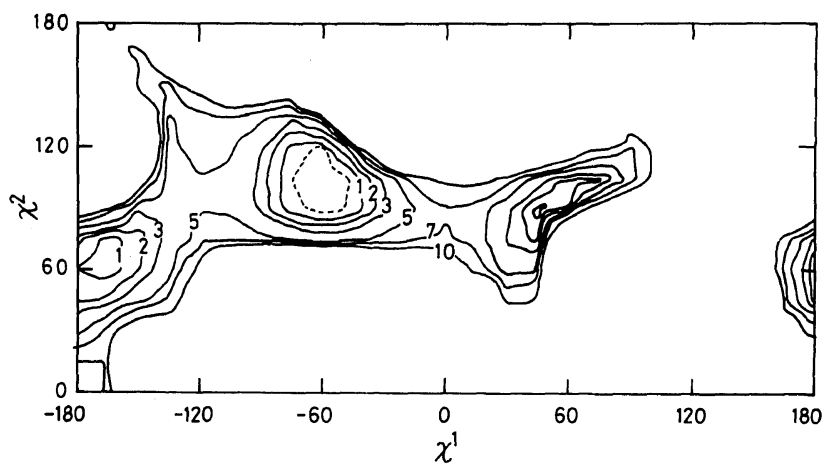

(c)

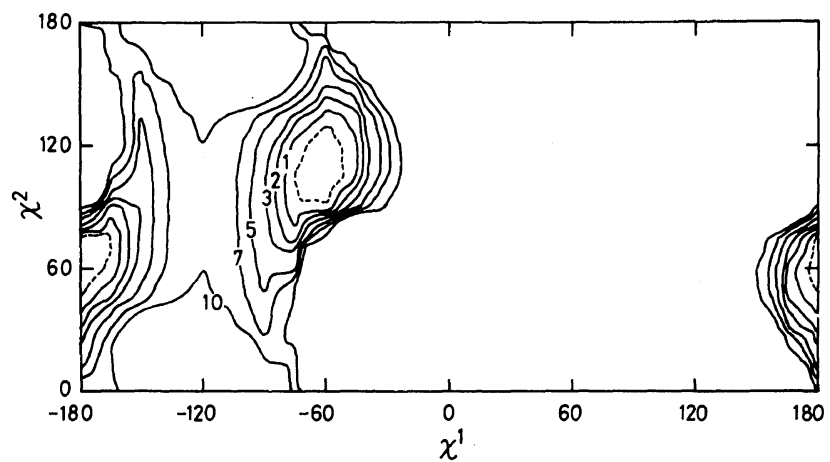

(d)

Figure 3 
Random-Coiled Conformation of Polypeptide I.

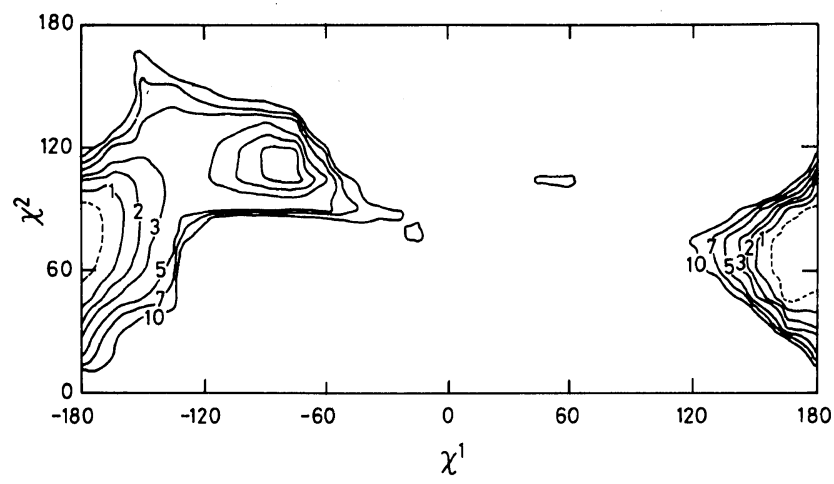

(e)

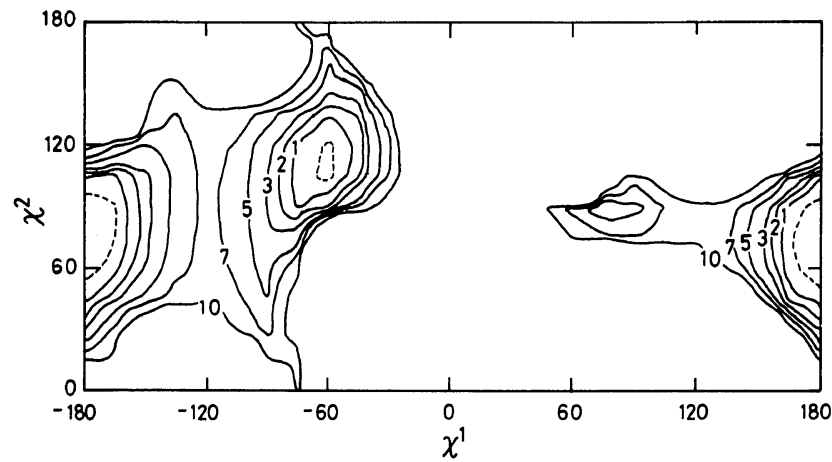

(f)

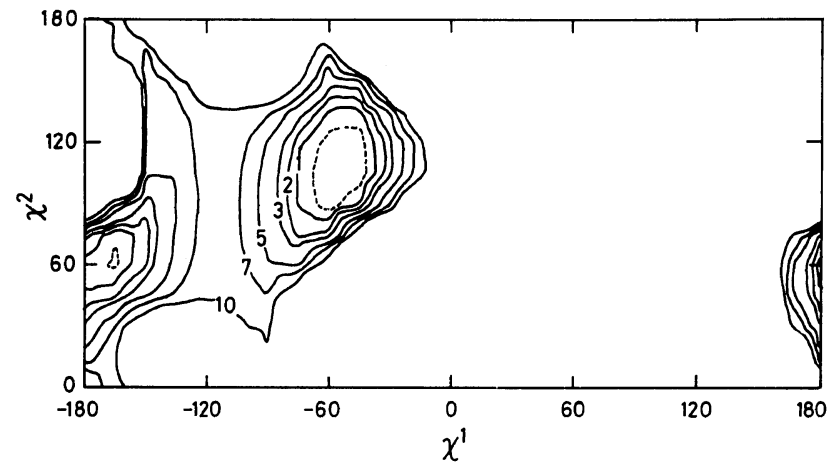

(g)

Figure 3. Energy contour $\left(\chi^{1}, \chi^{2}\right)$ maps of L-Phe residues for specified backbone conformations.

(a) E conformation: $(\phi, \psi)=\left(-155^{\circ}, 147^{\circ}\right)$ with $E_{\min }=-6.286 \mathrm{kcal} \mathrm{mol}^{-1}$.

(b) F conformation: $(\phi, \psi)=\left(-76^{\circ}, 139^{\circ}\right)$ with $E_{\min }=-5.553 \mathrm{kcal} \mathrm{mol}^{-1}$.

(c) D conformation: $(\phi, \psi)=\left(-147^{\circ}, 31^{\circ}\right)$ with $E_{\min }=-4.648 \mathrm{kcal} \mathrm{mol}^{-1}$.

(d) C conformation: $(\phi, \psi)=\left(-85^{\circ}, 79^{\circ}\right)$ with $E_{\min }=-5.148 \mathrm{kcal} \mathrm{mol}^{-1}$.

(e) G conformation: $(\phi, \psi)=\left(-162^{\circ},-53^{\circ}\right)$ with $E_{\min }=-4.139 \mathrm{kcal} \mathrm{mol}^{-1}$.

(f) A conformation: $(\phi, \psi)=\left(-74^{\circ},-37^{\circ}\right)$ with $E_{\min }=-4.853 \mathrm{kcal} \mathrm{mol}^{-1}$.

(g) A* conformation: $(\phi, \psi)=\left(49^{\circ}, 55^{\circ}\right)$ with $E_{\min }=-2.678 \mathrm{kcal} \mathrm{mol}^{-1}$.

These results indicate that $\left\langle R^{2}\right\rangle_{0, \infty} / n l^{2}$ depends on the value of the intervals, and also the $\left(15^{\circ}, 15^{\circ}\right)$ interval is a more desirable approximation for calculating $Z_{i}$ by eq 1 than the $\left(30^{\circ}, 30^{\circ}\right)$ and $\left(120,60^{\circ}\right)$ intervals. The calculated characteristic ratios of poly(L- 
M. OKa and A. NAKAJIMA

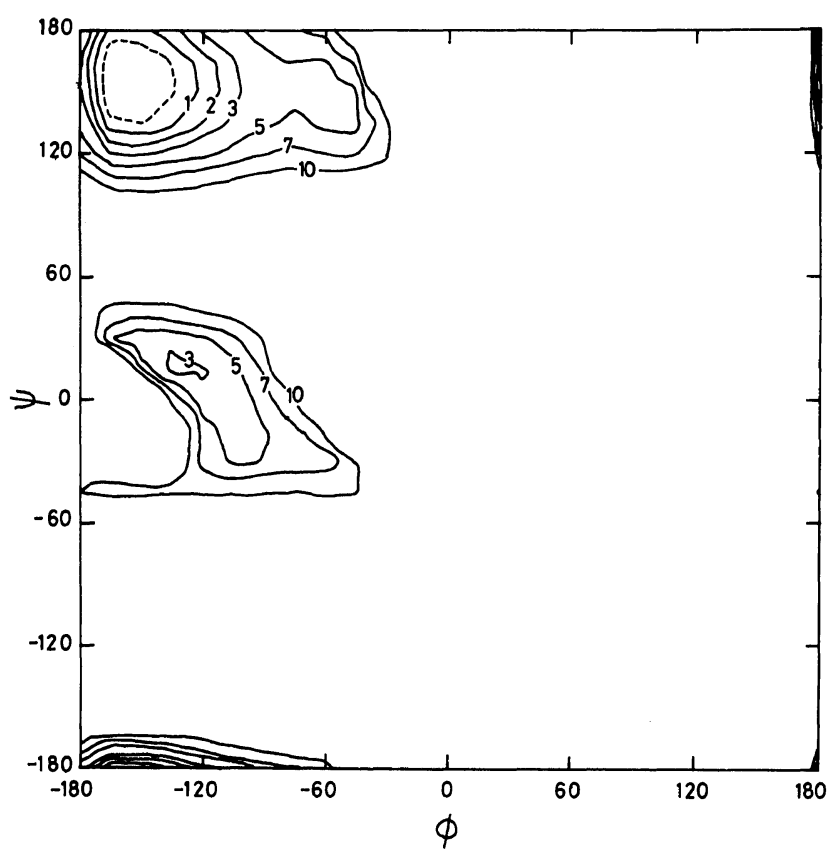

(a)

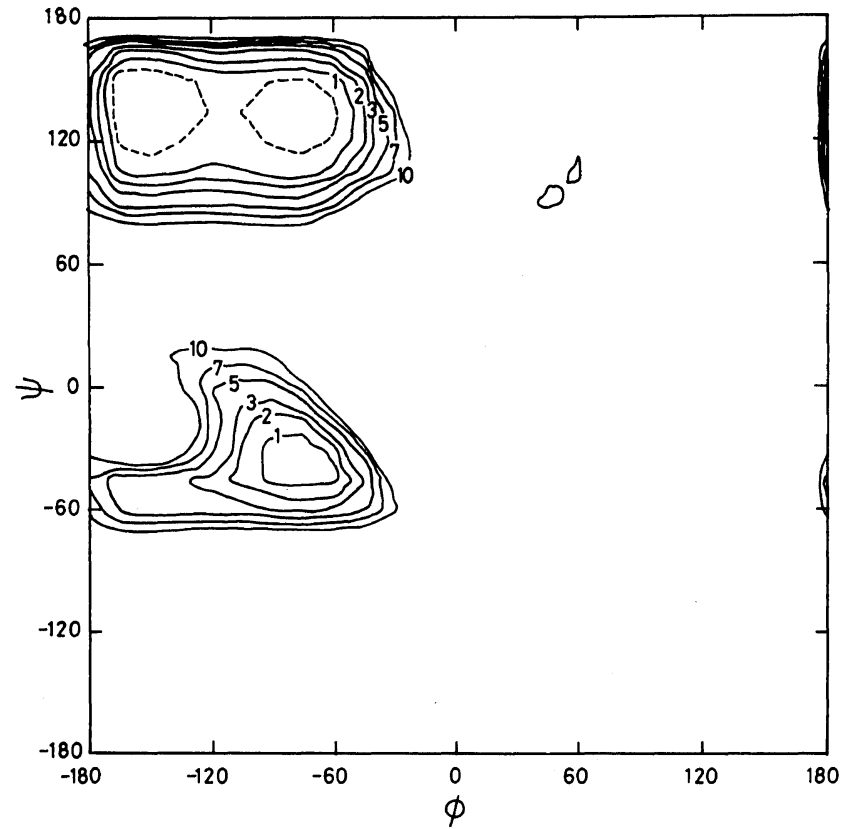

(b)

Figure 4 
Random-Coiled Conformation of Polypeptide I.

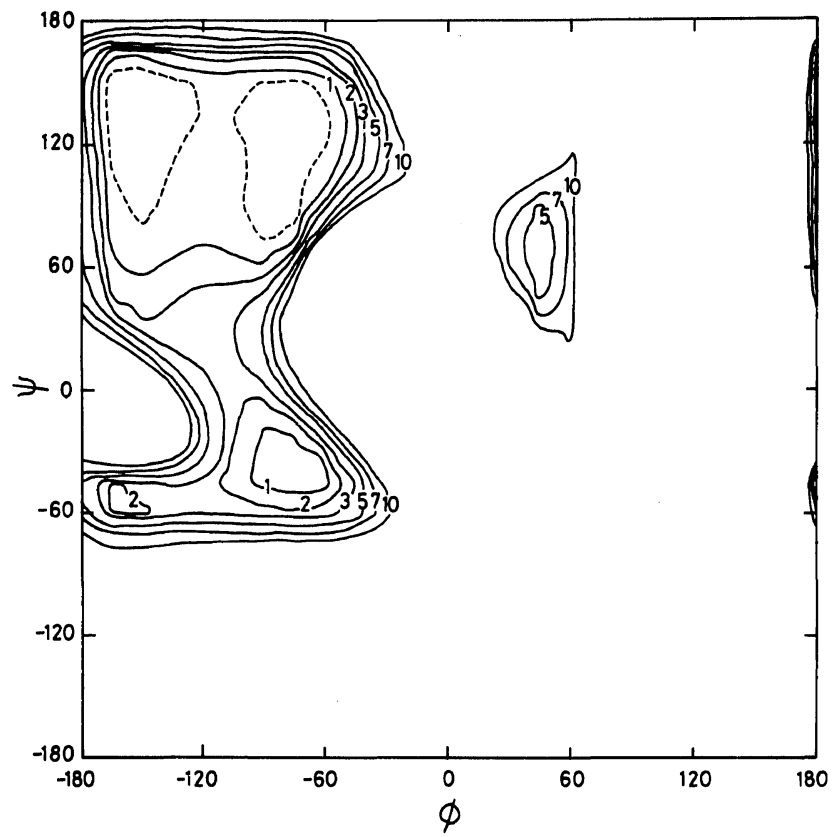

(c)

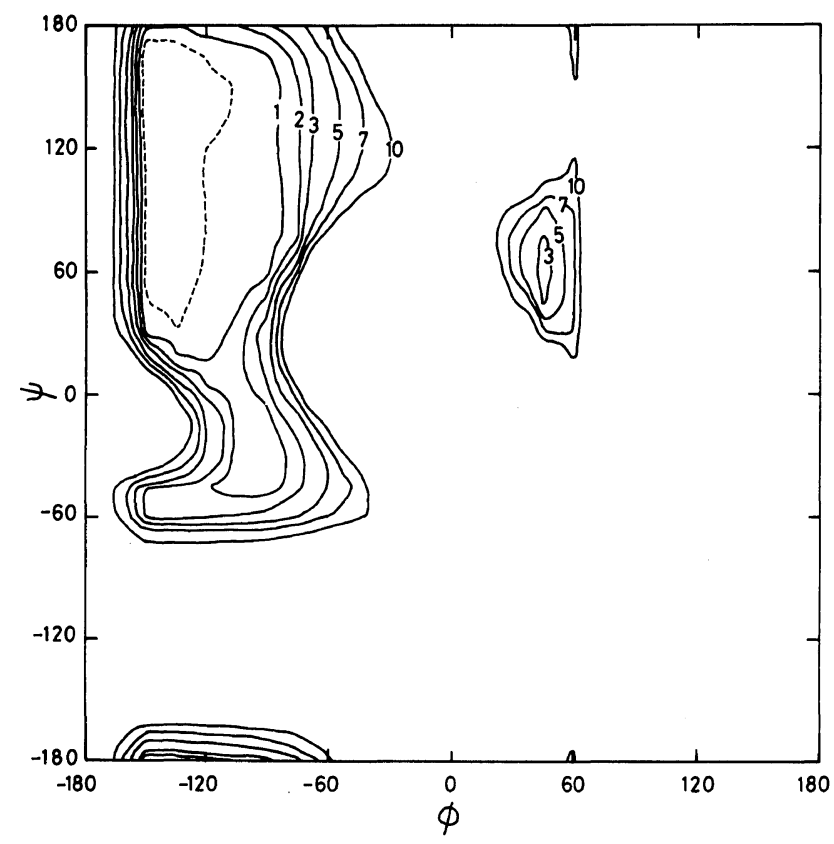

(d)

Figure 4 
M. OKa and A. NAKAJIMA

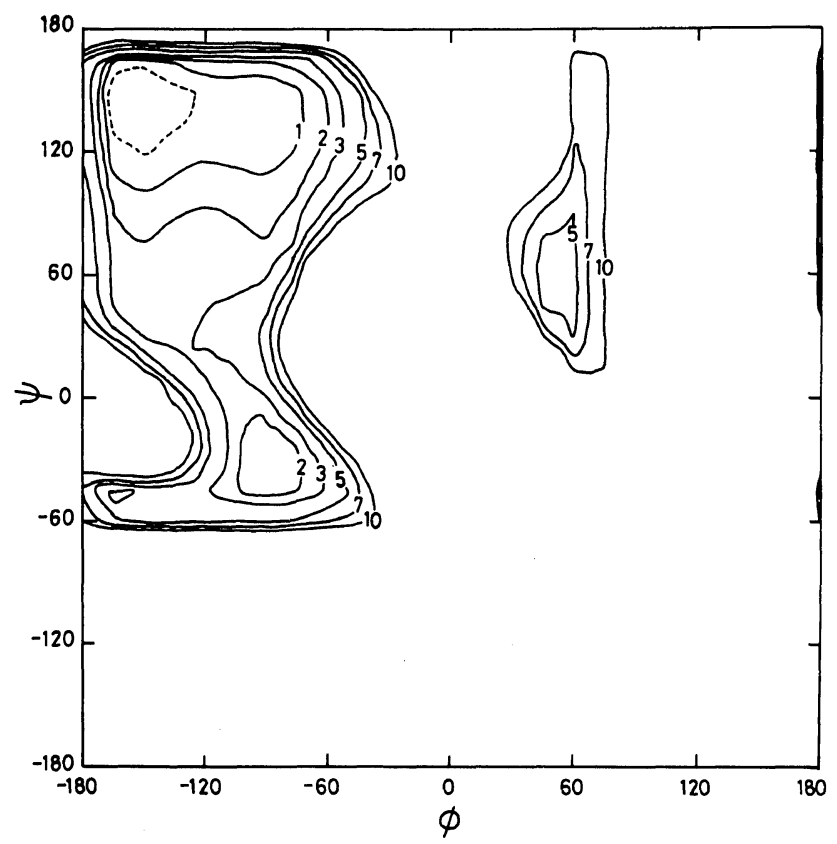

(e)

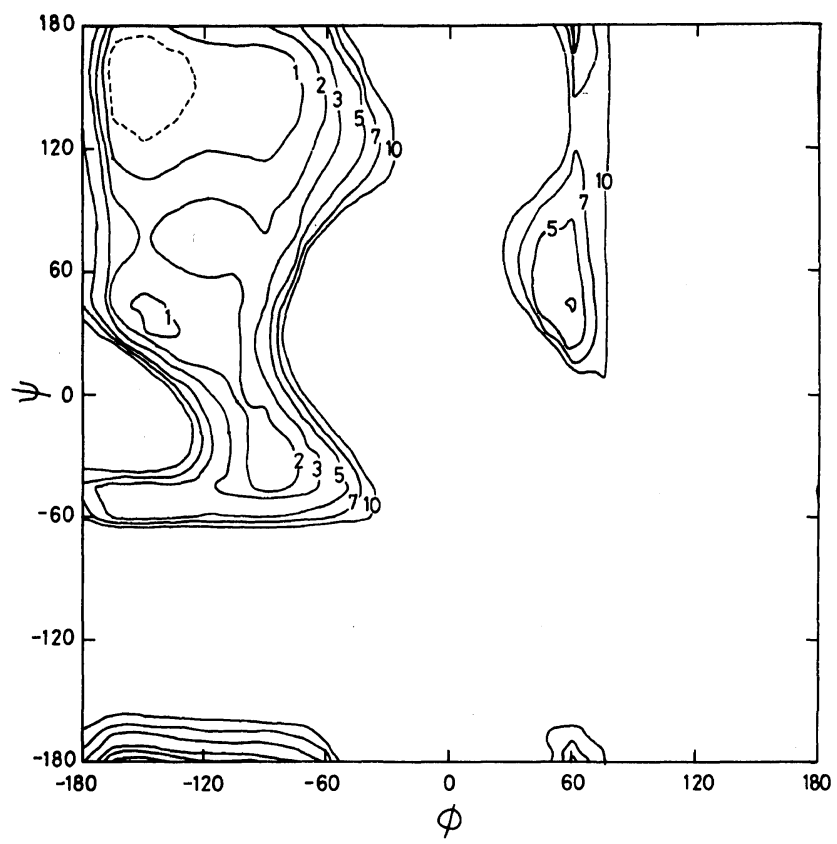

(f)

Figure 4 
Random-Coiled Conformation of Polypeptide I.

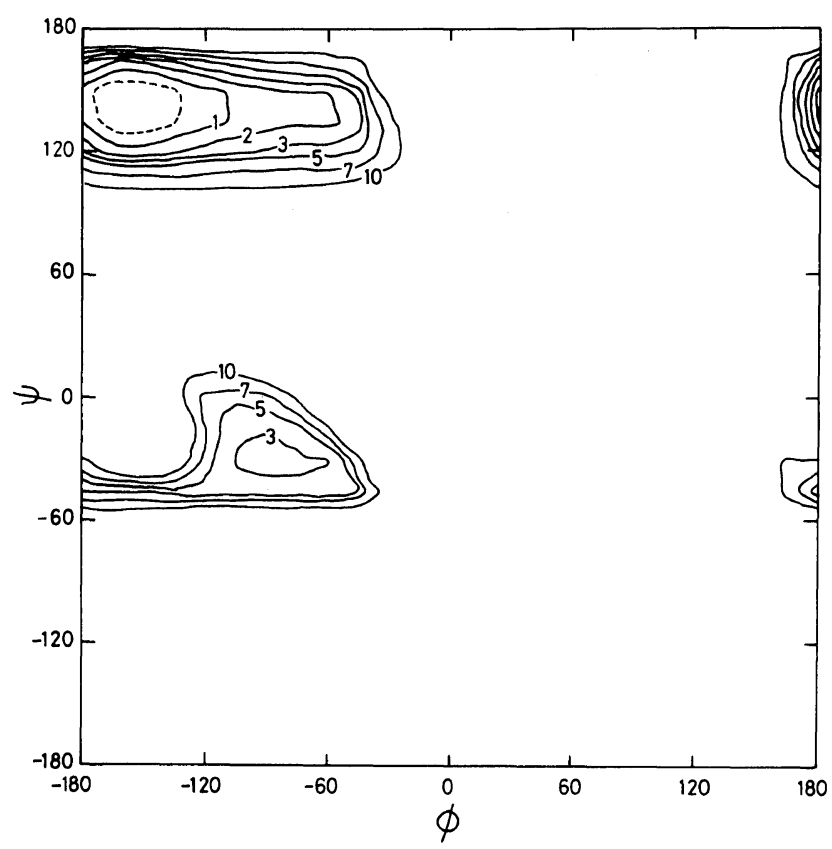

(g)

Figure 4. Energy contour $(\phi, \psi)$ maps of the L-Phe residue for a specified side-chain conformation.

(a) $\left(\chi^{1}, \chi^{2}\right)=\left(60^{\circ}, 90^{\circ}\right), E_{\min }=-5.983 \mathrm{kcal} \mathrm{mol}^{-1}$.

(b) $\left(\chi^{1}, \chi^{2}\right)=\left(180^{\circ}, 90^{\circ}\right), E_{\min }=-5.840 \mathrm{kcal} \mathrm{mol}^{-1}$.

(c) $\left(\chi^{1}, \chi^{2}\right)=\left(180^{\circ}, 60^{\circ}\right), E_{\min }=-5.711 \mathrm{kcal} \mathrm{mol}^{-1}$.

(d) $\left(\chi^{1}, \chi^{2}\right)=\left(-60^{\circ}, 90^{\circ}\right), E_{\min }=-5.353 \mathrm{kcal} \mathrm{mol}^{-1}$.

(e) $\left(\chi^{1}, \chi^{2}\right)=\left(-150^{\circ}, 90^{\circ}\right), E_{\min }=-4.067 \mathrm{kcal} \mathrm{mol}^{-1}$.

(f) $\left(\chi^{1}, \chi^{2}\right)=\left(-150^{\circ}, 60^{\circ}\right), E_{\min }=-3.616 \mathrm{kcal} \mathrm{mol}^{-1}$.

(g) $\left(\chi^{1}, \chi^{2}\right)=\left(150^{\circ}, 90^{\circ}\right), E_{\min }=-3.298 \mathrm{kcal} \mathrm{mol}^{-1}$.

phenylalanine) are remarkably higher than that of poly(L-alanine), and the L-Phe residue cannot be treated as an alanine-type residue because of its favorable side-chain/backbone interactions.

A similar trend is seen in the energy contour map of the L-Tyr residue shown in Figures $6 \mathrm{a}-\mathrm{c}$. The conformations with $\Delta E \leq 0.5 \mathrm{kcal}$ $\mathrm{mol}^{-1}$ are restricted only to the region $\mathrm{E}$. The $\mathrm{F}$ and $\mathrm{A}$ conformations of this residue are less stable than those of the L-Phe residue. However, the overall shapes of the $(\phi, \psi)$ maps of the L-Phe and L-Tyr residues are similar. The statistically averaged transformation matrices calculated from the energy contour maps in Figure $6 \mathrm{a}-\mathrm{c}$ are

$$
\begin{aligned}
& \langle\boldsymbol{T}\rangle_{\mathrm{L}-\mathrm{Tyr}}\left(120^{\circ}, 60^{\circ}\right)= \\
& {\left[\begin{array}{rrr}
0.606 & 0.240 & 0.569 \\
0.256 & -0.784 & 0.074 \\
0.624 & 0.033 & -0.583
\end{array}\right]} \\
& \langle\boldsymbol{T}\rangle_{\mathrm{L}-\mathrm{Tyr}}\left(30^{\circ}, 30^{\circ}\right)= \\
& \quad\left[\begin{array}{rrr}
0.548 & 0.146 & 0.615 \\
0.181 & -0.764 & 0.025 \\
0.673 & 0.013 & -0.498
\end{array}\right] \\
& \langle\boldsymbol{T}\rangle_{\mathrm{L}-\mathrm{Tyr}}\left(15^{\circ}, 15^{\circ}\right)= \\
& {\left[\begin{array}{rrr}
0.552 & 0.144 & 0.620 \\
0.198 & -0.766 & 0.021 \\
0.674 & 0.032 & -0.497
\end{array}\right],}
\end{aligned}
$$


M. OKa and A. NAKAJIMA

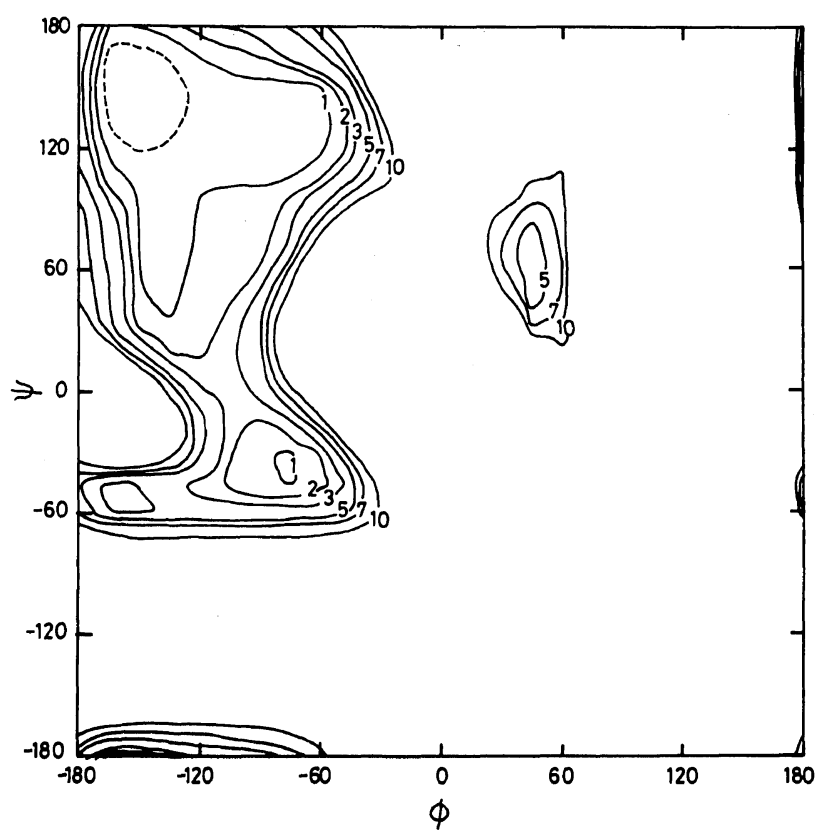

(a)

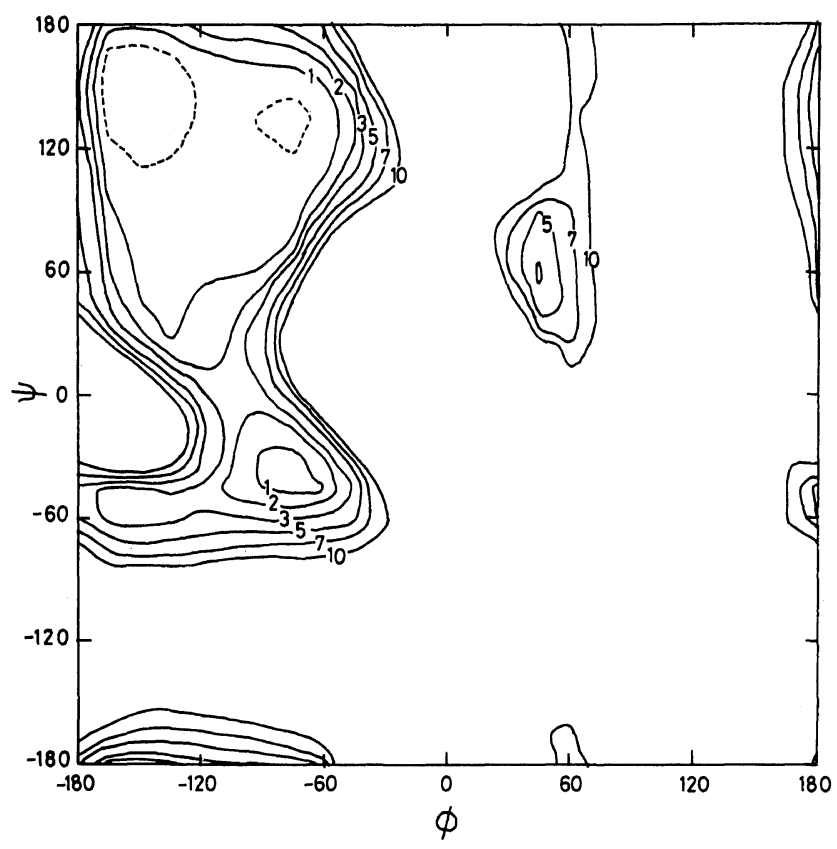

(b)

Figure 5 


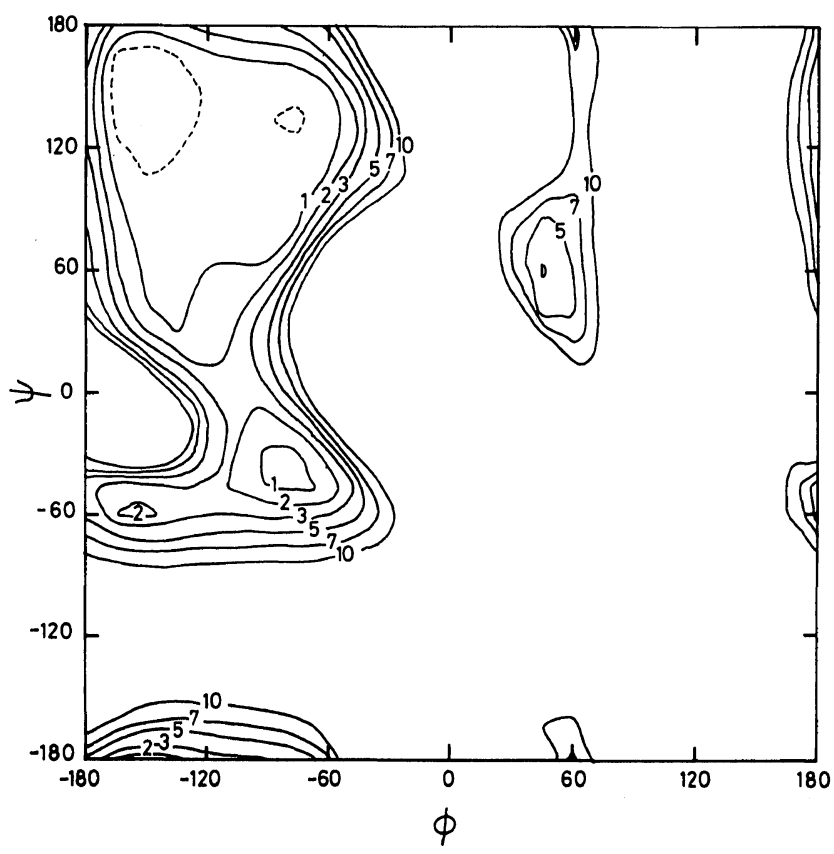

(c)

Figure 5. Energy contour $(\phi, \psi)$ maps of the L-Phe residue averaged over whole side-chain conformations.

(a) Averaged over the $\left(120^{\circ}, 60^{\circ}\right)$ interval.

(b) Averaged over the $\left(30^{\circ}, 30^{\circ}\right)$ interval

(c) Averaged over the $\left(15^{\circ}, 15^{\circ}\right)$ interval.

Table II. Theoretical and experimental results on the characteristic ratio of polypeptides

\begin{tabular}{|c|c|c|c|c|c|c|c|c|}
\hline \multirow{2}{*}{ Polypeptide } & \multicolumn{3}{|c|}{$\Omega$-Average ${ }^{\mathrm{a}}$} & \multirow{2}{*}{$w$-Average ${ }^{\mathrm{b}}$} & \multirow{2}{*}{$v$-Average ${ }^{c}$} & \multirow{2}{*}{ Tanaka $^{\mathrm{d}}$} & \multirow{2}{*}{ Flory $^{\mathrm{e}}$} & \multirow{2}{*}{ Experimental } \\
\hline & $\left(15^{\circ}, 15^{\circ}\right)$ & $\left(30^{\circ}, 30^{\circ}\right.$ & $\left(20^{\circ}, 60^{\circ}\right)$ & & & & & \\
\hline Gly & 2.15 & & & & & 2.17 & 2.16 & \\
\hline Ala & 8.15 & & & & & $(8.38)^{f}$ & $(9.27)^{f}$ & \\
\hline Phe & 11.24 & 10.71 & 13.20 & 10.95 & 12.40 & & & \\
\hline Tyr & 12.33 & 11.58 & 14.48 & 11.28 & 12.93 & & & $12.3^{\mathrm{g}}$ \\
\hline
\end{tabular}

a Averaged value with the summation of Boltzman factors at $15^{\circ}$ intervals of $(\phi, \psi)$, and at $\left(15^{\circ}, 15^{\circ}\right),\left(30^{\circ}, 30^{\circ}\right)$, and $\left(120^{\circ}, 60^{\circ}\right)$ intervals of $\left(\chi^{1}, \chi^{2}\right)$, respectively.

b Averaged value with the summation of statistical weights at minimum-energy points. ${ }^{13}$

c Averaged value with the summation of Boltzmann factors at minimum-energy points. ${ }^{13}$

d From ref 7.

e From ref 2.

$\mathrm{f}$ Values for a polypeptide composed of alanine-type residues, using the $\beta$-methylene group approximation.

g Evaluated results from the experimental results of ref 23 .

and the calculated characteristic ratios ratios are $14.48,11.58$ and 12.33 for the $\left(120^{\circ}, 60^{\circ}\right)$, $\left(30^{\circ}, 30^{\circ}\right)$ and $\left(15^{\circ}, 15^{\circ}\right)$ intervals, respectively.

\section{DISCUSSION}

The calculated characteristic ratio of 2.15 
M. OKa and A. NaKajima

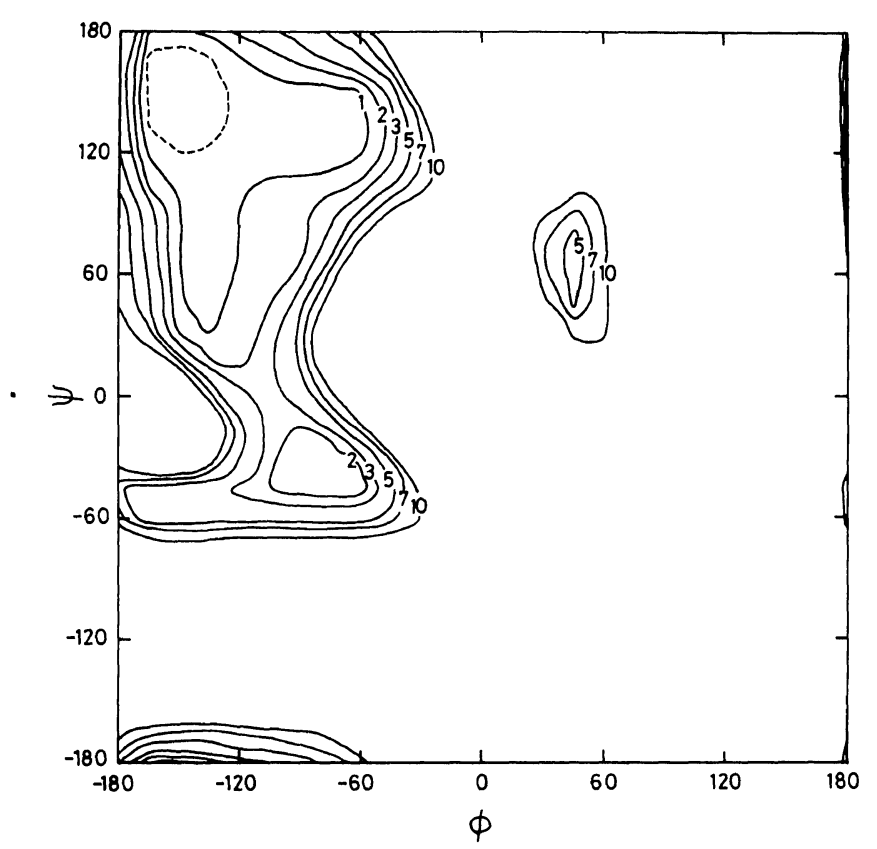

(a)

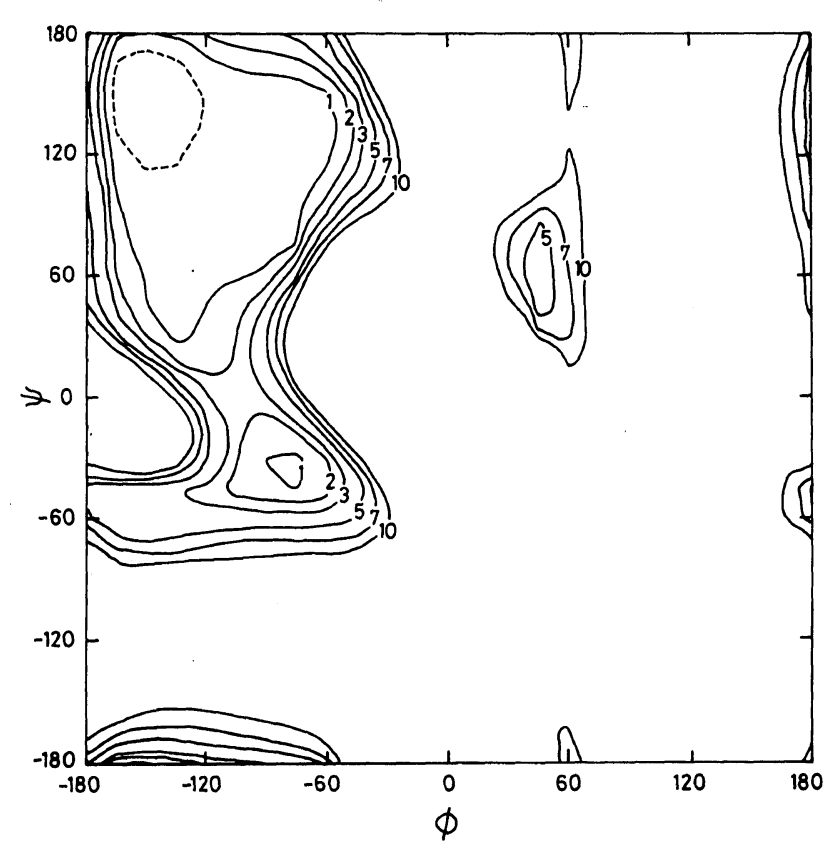

(b)

Figure 6 


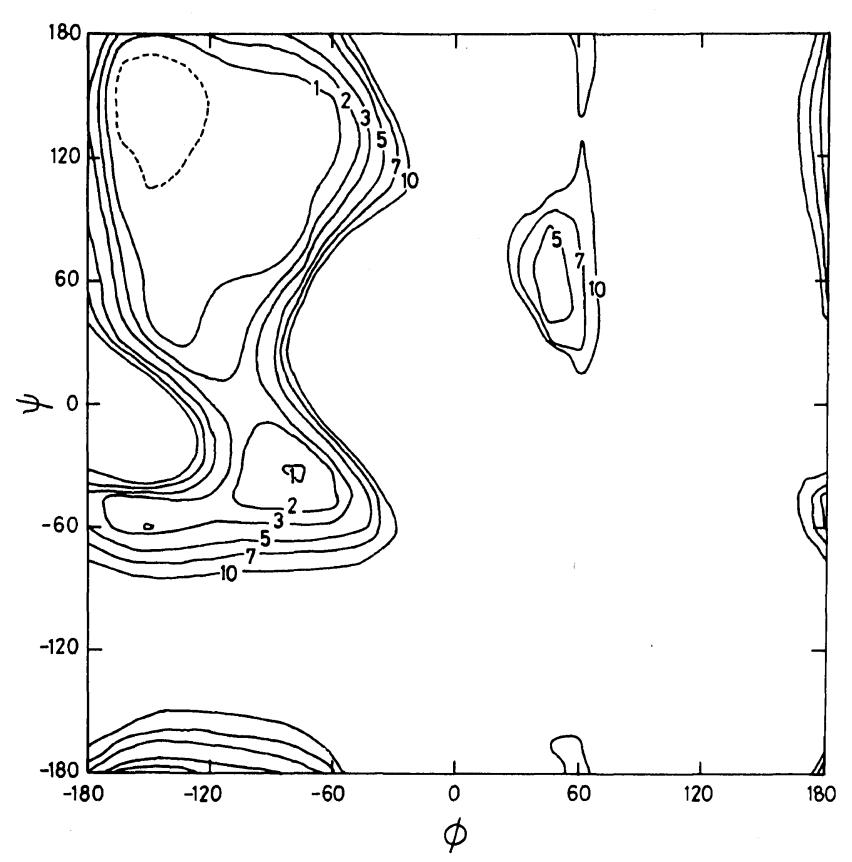

(c)

Figure 6. Energy contour $(\phi, \psi)$ maps of the L-Tyr residue averaged over whole side-chain conformations.

(a) Averaged over the $\left(120^{\circ}, 60^{\circ}\right)$ interval.

(b) Averaged over the $\left(30^{\circ}, 30^{\circ}\right)$ interval.

(c) Averaged over the $\left(15^{\circ}, 15^{\circ}\right)$ interval.

for poly(glycine) is in excellent agreement with the previous results of Brant et al. ${ }^{2}$ (2.16), and Tanaka and $\mathrm{Nakajima}^{7}$ (2.17) inspite of the difference in energy parameters and molecular geometry used. The calculated characteristic ratio (8.15) of poly(L-alanine) is close to Tanaka-Nakajima's value ${ }^{7}$ (8.38), but lower than that of Brant et al. ${ }^{2}$ (9.27). However, in their work, ${ }^{1,2}$ the characteristic ratio was treated as a function of the van der Waals radius of the $\beta$-methylene group $\left(r_{\mathrm{CH}_{2}}\right)$, and they obtained 9.27 for $r_{\mathrm{CH}_{2}}=1.85 \AA$. Sasisekharan proposed $r_{\mathrm{CH}_{2}}=1.80-1.85 \AA$ as reasonable values from an analysis of $\mathrm{X}$-ray crystallographic data. ${ }^{22}$ Because L-Ala residue has the smallest side-chain group among the alanine-type residues, the van der Waals radius of methyl group of L-Ala residue is expected to take the lowest value of this proposed range. A value of
8.2 was estimated for the characteristic ratio from Figure 4 of reference 1 for $r_{\mathrm{CH}_{2}}=1.80 \AA$. Reasonable agreement between the results in this and the previous work ${ }^{1,2,7}$ indicates that ECEPP can be applied to the theoretical analysis of a polypeptide chain in solution although the energy parameters and geometry used in ECEPP are mainly determined by experimental results on oligopeptides and their model molecules and not by those on polypeptides in solution.

It is noted that the calculated characteristic ratio (12.33) of poly(L-tyrosine) is in good agreement with the experimental result $(12.3)^{23,24}$ for poly $(O$-carbobenzoxy-L-tyrosine). Fairly good agreement between theoretical and experimental results indicates that the intra-residue interactions are very important for poly(L-tyrosine) in the random-coiled 
state, and major contributions to the intraresidue interactions are the interactions between the phenyl group and backbone. Since poly(L-tyrosine) has large side-chain groups, favorable interactions are expected to take place among different residues. However, theoretical analysis of L-Phe-L-Phe dipeptide and L-Phe-L-Phe-L-Phe tripeptide ${ }^{15}$ indicates that the global effects of these inter-residue interactions on unperturbed chain dimensions are almost negligible even if the distribution of energetically favorable conformations for residues in di- and tripeptides are influenced by these inter-residue interactions.

As already mentioned in the Results section, the remarkably large characteristic ratios calculated for poly(L-tyrosine) and poly(Lphenylalanine) indicate that these polymers cannot be treated as alanine-type polymers, and also that use of the residues, which can be treated by the $\beta$-methylene group approximation, may be more limited than considered so in the previous work. ${ }^{1-8}$ Moreover, L-Tyr and L-Phe residues tend to form more extended backboen conformations compared to the L-Ala residues. This tendency may also be predicted from the energy contour maps in Figures $5 \mathrm{a}-\mathrm{c}$ and $6 \mathrm{a}-\mathrm{c}$ and is compatible with the $\beta$-sheet forming tendency ${ }^{27}$ of L-Tyr and L-Phe in proteins as deduced by X-ray crystallography.

As shown in Figures $5 \mathrm{a}-\mathrm{c}$ and $6 \mathrm{a}-\mathrm{c}$ and Table II, energetically stable regions of L-Phe and L-Tyr in the $(\phi, \psi)$ map averaged over the side-chain conformations and characteristic ratio depend on the intervals of $\chi^{1}$ and $\chi^{2}$. The $\left(120^{\circ}, 60^{\circ}\right)$ interval is not sufficient to obtain a reasonable characteristic ratio averaged over the whole conformational space. Energetically stable regions of $\mathrm{L}-\mathrm{Phe}$ and $\mathrm{L}-\mathrm{Tyr}$ residues broadly distribute about $\chi^{2}= \pm 90^{\circ}$, as shown in Figures $3 \mathrm{a}-\mathrm{g}$ and the tables of conformational energy-minima ${ }^{13}$ of Ac-L-PheNHMe and Ac-L-Tyr-NHMe. Therefore, the $\left(15^{\circ}, 15^{\circ}\right)$ or $\left(30^{\circ}, 30^{\circ}\right)$ intervals of $\left(\chi^{1}, \chi^{2}\right)$ are desirable when averaging over the side-chain conformations.

As discussed in ref 28, the statistical average of a conformation-dependent quantity can be obtained by the classical conformational integral over the whole conformational space. However, calculation of this integral is not feasible from a practical point of view. Actually, one may use three approximated methods, namely, 1) summation of Boltzmann factors at intervals over the whole conformational space, 2) summation of statistical weights at minimum-energy points, and 3) summation of Boltzmann factors at minimumenergy points. The second and third averages were also calculated for poly(L-phenylalanine) and poly(L-tyrosine), using the calculated statistical weights and Boltzmann factors of the single residue minima. ${ }^{13}$ As shown in Table II, the averaged values based on the statistical weights are lower and those based on the Boltzmann factors are higher than the averaged value at $15^{\circ}$ intervals over the whole $\left(\phi, \psi, \chi^{1}\right.$, $\left.\chi^{2}\right)$ space.

Acknowledgements. We should like to thank Professor H. A. Scheraga, Department of Chemistry, Cornell University, for presenting the program, ECEPP.

Computations were carried out by the FACOM M-380 Computer in the Data Processing Center, Kyoto University.

\section{REFERENCES AND NOTES}

1. D. A. Brant and P. J. Flory, J. Am. Chem. Soc., 87, 2791 (1965).

2. D. A. Brant,' W. G. Miller, and P. J. Flory, J. Mol. Biol., 23, 47 (1967).

3. W. G. Miller, D. A. Brant, and P. J. Flory, J. Mol. Biol., 23, 67 (1967).

4. P. Schimmel and P. J. Flory, Proc. Natl. Acad. Sci. U.S.A., 58, 52 (1967).

5. P. Schimmel and P. J. Flory, J. Mol. Biol., 34, 105 (1968).

6. S. Tanaka and A. Nakajima, Polym. J., 1, 71 (1970).

7. S. Tanaka and A. Nakajima, Polym. J., 2, 717 (1971).

8. S. Tanaka and A. Nakajima, Polym. J., 2, 725 (1971).

9. D. A. Brant and P. J. Flory, J. Am. Chem. Soc., 87, 2788 (1965). 
10. H. Fujita, A. Teramoto, T. Yamashita, K. Okita, and S. Ikeda, Biopolymers, 4, 781 (1966).

11. M. Terbojevich, E. Peggion, A. Cosani, G. D'Este, and E. Scoffone, Eur. Polym. J., 3, 681 (1967).

12. W. G. Miller and C. V. Goebel, Biochemistry, 7, 3925 (1968).

13. S. S. Zimmerman, M. S. Pottle, G. Nemethy, and H. A. Scheraga, Macromolecules, 10, 1 (1977).

14. M. Oka, G. T. Montelione, and H. A. Scheraga, submitted to J. Am. Chem. Soc.

15. M. Oka and A. Nakajima, to be submitted to Polym. $J$.

16. F. A. Momany, R. F. McGuire, A. W. Burgess, and H. A. Scheraga, J. Phys. Chem., 79, 2361 (1975).

17. IUPAC-IUB Commission on Biological Nomenclature, Biochemistry, 9, 3471 (1970).

18. P. J. Flory, "Statistical Mechanics of Chain Molecules," John Wiley \& Sons, New York, N.Y., 1969.

19. M. Oka and A. Nakajima, unpublished data.

20. E. Benedetti, C. Pedone, C. Toniolo, G. Nemethy, M. S. Pottle, and H. A. Scheraga, Int. J. Peptide
Protein Res., 16, 156 (1980).

21. G. Nemethy, M. S. Pottle and H. A. Scheraga, $J$. Phys. Chem., 87, 1883 (1983).

22. V. Sasisekharan, "Collagen," N. Ramanathan, Ed., John Wiley \& Sons, New York, N.Y., 1962, p 39.

23. J. P. Vollmer and G. Spach, Biopolymers, 5, 337 (1967).

24. This value was estimated using the experimental results of ref 23 and the universal constant $\Phi_{0}=$ $2.5 \times 10^{21}$, which is the currently most reasonable value as mentioned at page 364 in ref 25 . A slightly larger value 13.0 than this was presented in Table IV of ref 26 in which $\Phi_{0}=2.3 \times 10^{21}$ was used to calculate.

25. H. Yamakawa, "Modern Theory of Polymer Solutions," Harper \& Row, New York, N.Y., 1971.

26. A. Teramoto and H. Fujita, Adv. Polym. Sci., 18, 65 (1975).

27. P. Y. Chou and G. Fasman, Adv. Enzym., 47, 45 (1978).

28. S. S. Zimmerman, L. L. Shipman, and H. A. Scheraga, J. Phys. Chem., 81, 614 (1977). 